\title{
Prognostic Accuracy of a Novel Prognostic Score Using a Combination of PCT, DDi, and Lactate Biomarkers in Patients With Sepsis: A Retrospective Cohort Study
}

\author{
Yansong miao \\ Zhejiang University \\ LiFeng Xing ( $\mathbf{0} 3416231 @ z j u . e d u . c n)$ \\ Zhejiang University
}

\section{Research Article}

Keywords: Sepsis, Emergency department, Prediction model, Prognosis, Biomarkers

Posted Date: November 2nd, 2021

DOI: https://doi.org/10.21203/rs.3.rs-960482/v1

License: (c) (i) This work is licensed under a Creative Commons Attribution 4.0 International License.

Read Full License 


\section{Abstract \\ Background}

A combination of multiple biomarkers will be more accurate in predicting the mortality of sepsis patients. Herein, we aimed to assess the ability to predict adverse outcomes of a novel scoring system using the combination of PCT, DDi, and lactate (PDLS) in patients with sepsis from the emergency department (ED) of a hospital.

\section{Methods}

The patients' baseline characteristics, main laboratory data and outcome were collected from the patient's electronic medical record. A receiver operating characteristic curve (ROC) analysis determine the optimal cutoff points for biomarkers PCT, DDi and lactate and establish a PDLS system based on their cutoff points. ROC was used to compare the accuracy of PDLS to Sequential Organ Failure Assessment (SOFA) and Acute Physiology and Chronic Health Evaluation (APACHE) II scores in predicting short-term mortality in patients with sepsis.

\section{Results}

The analysis cohort included 1001 patients. 117 sepsis patients died in 28 days. An increase in PDLS was associated with higher mortality and adverse events including MV, VD, AICU, and CRRT. PDLS was an independent predictor of 28-day mortality, MV, VD, AICU, and CRRT. The Area Under the Receiver Operating Characteristic curve (AUROC) of PDLS $(0.96 ; \mathrm{Cl}=0.94-0.98)$ was significantly higher than that of SOFA (0.84; $\mathrm{Cl}=0.80-0.89)$ and APACHE II $(0.84 ; \mathrm{Cl}=0.79-0.88)$.

\section{Conclusion}

PDLS is an independent prognostic predictor of adverse clinical outcomes for sepsis patients and was superior to other prognostic scores, including SOFA and APACHE II.

\section{Background}

Sepsis is defined as a life-threatening organ dysfunction due to an unregulated host response to infection[1].The World Health Organization (WHO) marked sepsis as the most urgent unmet medical need of our time[2]. The incidence of severe sepsis continues to increase and has become a significant health care problem[3-5]. The mortality rate of severe sepsis was reported to be as high as $30 \%[6-8]$. Notably, the emergency departments (ED) are the main entrance for sepsis patients into the hospital $[9,10]$. When targeted treatment and supportive measures are delayed, the mortality rate of sepsis will increase[11, 12] 
At present, different warning and classification systems, severity scores, and preventive measures have been used to help clinicians identify sepsis early and improve the management of sepsis.

The severity scoring systems for sepsis mainly include the Acute Physiology and Chronic Health Evaluation (APACHE) II score[13], sequential organ failure assessment (SOFA) score[14], quick sequential organ failure assessment (qSOFA)[14], systemic inflammatory response syndrome (SIRS) score[15], Modified Early Warning Score (MEWS)[16] and Mortality in Emergency Department Sepsis Score (MEDS) [17]. APACHE II score is a critical scoring standard for assessing the risk of critically ill patients[18]. However, it is established that this score can provide erroneous values in some patients, such as in elderly patients with chronic organ failure or comatose patients where the score is exceedingly high. Therefore, when the APACHE II score was applied to clinical practice, its negative predictive value for predicting death did not get the clinician's heartfelt satisfaction[13]. Although SOFA shows more remarkable ability in the ICU unit than qSOFA, most patients with sepsis are initially in a non-ICU environment, and for this reason, it is rarely used outside of ICU or in the early stages of sepsis[19]. In addition, the qSOFA score is used as the initial predictor of sepsis outside the ICU, especially in the These data were"in North American and Germany cohorts[20], but were not externally validated. On top of their relative complexity, these scoring systems lack specific biomarkers for diagnosing and monitoring sepsis patients. Therefore, a novel and reproducible prognostic tool for ED sepsis is imperative for swiftly identifying sepsis in patients.

The prevailing theory has been that sepsis represents an uncontrolled inflammatory response[21]. Different cytokines, peptides, and other signaling molecules that act as biomarkers are elevated at different stages of sepsis and can be detected in the bloodstream. More than 100 different biomarkers have been studied, none of which have been used clinically except procalcitonin (PCT) and C-reactive protein (CRP) $[22,23]$. PCT has been widely used as a sepsis biomarker in the diagnosis, risk stratification, prognosis, and monitoring of treatment effects in recent years. PCT has the ability to predict the prognosis of sepsis and is correlated with bacterial load[24-26]and severity of the infection[27-29]. Clotting abnormalities often occur in patients with sepsis and may play a significant role in the clinical outcomes of critically ill patients[30]. As a candidate biomarker of sepsis, fibrin D-dimer (DDi) stands apart in its availability in the ED. It demonstrated adequate sensitivity for sepsis in ICU patients[31, 32]. Traditionally, lactate was perceived as the end product of anaerobic metabolism primarily in skeletal muscle, a concept known as the "oxygen debt model" that first emerged in the 1920s[33]. Among its numerous uses as a diagnostic test, lactate level has long been used as a marker of recovery, risk stratification, and a tool for predicting mortality from sepsis. New research identifies lactate as an independent prognostic predictor of mortality for patients with sepsis. Moreover, it has superior discriminative power than qSOFA while showing a discriminative ability similar to that of SOFA[34]

Different clinical scoring systems have been validated for ED. However, when the life parameters are abnormal, the patient may already be in the advanced stage of sepsis. Using biomarkers to detect sepsis can detect the early stage of sepsis before abnormal vital signs are recorded. Since multiple biomarkers have been studied, there is even more potential for combinations of biomarkers and clinical scoring 
systems. This study aimed to combine biomarkers into a new PCT + DDI + lactate score (PDLS) to predict short-term adverse outcomes in sepsis patients.

\section{Methods}

\section{Study design, setting, and population}

The vital signs on admission, medical history, laboratory data, final diagnosis data, adverse events including mechanical ventilation (MV), vasoactive drugs (VD), admission to intensive care unit (AICU), and continuous renal replacement therapy (CRRT), demographic data, APACHE II and SOFA data were extracted from the medical database of Sir Run Run Shaw Hospital of Zhejiang University. The singlecenter database retrospectively included the data of all adults ( $\geq 18$ years old) patients with sepsis in the ED from July 2017 to June 2020. only patients first diagnosed with sepsis under sepsis-3[14]criteria were eligible for inclusion. In addition, we excluded patients with missing data (no data on PCT, DDi, and lactate levels, or significant laboratory tests were recorded in Table 1 and patients younger than 18 years of age. Finally, we identified 1001 patients who met the inclusion criteria for our cohort. The detailed process of data extraction is shown in Figure.1.

\section{Establishing Pdls System And Follow-up}

According to the best cut off points of PCT, DDI and lactate to construct a PDLS system with a range of 03. Detailed scoring rules are shown in Table2. All patients with sepsis were followed up for 28 days. The primary endpoint was all-cause mortality during follow-up.

\section{Statistical analysis}

Categorical variables were presented as frequencies and percentages, whereas continuous variables were presented as medians and interquartile range (IQR) because the data are non-normally distributed. The time-dependent receiver operating characteristic (ROC) curves were constructed to compare the prognostic performance and determine the optimal cutoff points for biomarkers including PCT, DDi, and lactate and score system for PDLS, APACHE II, and SOFA. Patient characteristics were then compared based on PDLS using Kruskal-Wallis $\mathrm{H}$ tests; categorical data were compared using $\chi 2$-tests.

Multivariable logistic regression models were used to investigate the relationship between the PDLS and the different end points. A $P$-value $<0.01$ was considered statistically significant. Data analyses were performed using SPSS version 26.0 (IBMCorp, Armonk, NY, USA).

\section{Results}

\section{Baseline characteristics}


A total of 1023 patients with sepsis participated in the study; however, 22 patients were lost during followup and were excluded from the study. Therefore, 1001 patients were included in the study; The median age of enrollment was 73 (IQR 61-83) years; $64.2 \%$ of patients were male. A total of 117 patients died within 28 days. PCT, DDi and lactate levels were significantly higher in the survivor group, compared to the non-survivor group (PCT median $1.5 \mathrm{ng} / \mathrm{L}$ vs. $24.2 \mathrm{ng} / \mathrm{L}$; DDi median $1.8 \mu \mathrm{mol} / \mathrm{L}$ vs. $5.9 \mu \mathrm{mol} / \mathrm{L}$; lactate median $1.6 \mathrm{mmol} / \mathrm{L}$ vs. $5.6 \mathrm{mmol} / \mathrm{L}$, all $p \otimes 0.01)$. The survival group had lower APACHE (median 14 vs. $25, p \otimes 0.01$ ) and SOFA (median 3 vs. $11, p \llbracket 0.01$ ) scores compared to the mortality group and lower rate of MV, AICU, VD and CRRT (19.2\% vs. $94.0 \%, 35.9 \%$ vs. $97.4 \%, 10.2 \%$ vs. $88.0 \%, 6.2 \%$ vs. $61.2 \%$ respectively). Detailed data are shown in Table 1.

\section{Calculation of the PDLS}

According to the cut-off value determined by ROC curve analysis, PCT, DDI, and lactate were divided into two groups. Therefore, the recommended cut-off values for PCT $(8.12 \mathrm{ng} / \mathrm{L})$, DDi $(3.59 \mu \mathrm{mol} / \mathrm{L})$, and Lactate $(2.65 \mathrm{mmol} / \mathrm{L})$ are based on the maximum of Youden's index was used to calculate PDLS. The method of calculating PDLS is shown in Table 2.

\section{PDLS and the severity of sepsis}

According to PDLS, the clinical characteristics of sepsis patients are shown in Table 3. Heart rates and respiratory rates, temperature, WBC, BUN, and creatinine significantly increased with an increase in PDLS. Conversely, diastolic blood pressure (DBP), systolic blood pressure (SBP), $\mathrm{PH}$, partial pressure of oxygen $\left(\mathrm{PO}_{2}\right)$, Platelet, albumin significantly decreased with increasing PDLS.

Patients with sepsis having higher PDLS also had higher sofa and APACHE II scores than those with lower PDLS. For patients with PDLS of 0,1 , 2, and 3 , the median APACHEIl scores were 13 (IQR 9-18), 17 (IQR 12-23), 20 (IQR 13-28), and 25 (IQR 20-30), respectively $(P<0.01)$. The median SOFA scores were 3 (IQR 2-4), 4 (IQR 3-6), 6 (IQR 4-11) and 11 (IQR 7-15) (P<0.01), respectively. With the increase of PDLS, the 28-day mortality, MV, AICU, VD and CRRT rates increased gradually. The 28-day mortality rate of patients with scores of $0,1,2$ and 3 were $0.2 \%, 2.4 \%, 18.0 \%$, and $92.2 \%$, respectively $(p<0.01)$; MV were $11.3 \%, 30.2 \%, 51.7 \%$ and $93.1 \%$, respectively $(\mathrm{p}<0.01)$; AICU were $25.6 \%, 48 \%, 75.3 \%$ and $98.0 \%$, respectively $(p<0.01)$; VD were $4.3 \%, 16.3 \%, 46.1 \%$ and $85.3 \%$, respectively $(p<0.01)$; CRRT were $2.9 \%$, $8.7 \%, 29.2 \%$ and $61.8 \%$, respectively $(p<0.01)($ Table 3$)$.

\section{PDLS is an independent prognostic factor in patients with sepsis}

Univariate logistic regression model revealed that PDLS was positively correlated with the risk of mortality, MV, VD, and AICU. After adjusting for these potential confounders in the multivariate logistic regression analysis, the PDLS was independently associated with 28-day mortality $(O R=21.60,95 \% \mathrm{Cl}$ $=11.02-42.34, \mathrm{p}<0.01), \mathrm{MV}(\mathrm{OR}=2.88,95 \% \mathrm{Cl}=2.20-3.77, \mathrm{p}<0.01), \mathrm{AICU}(\mathrm{OR}=2.49,95 \% \mathrm{Cl}=1.99-3.11, \mathrm{p}<$ 0.01), VD (OR=2.89, 95\% Cl=2.22-3.75, $p<0.01)$ and $\mathrm{CRRT}(\mathrm{OR}=1.91,95 \% \mathrm{Cl}=1.44-2.54, \mathrm{p}<0.01)$ (Table 4). 


\section{Comparison of PDLS to SOFA and APACHE II scores}

The differentiation of 28-day mortality as assessed by AUROC (Figure 2; Table 5) indicates that PDLS (AUROC, 0.96) was significantly higher than SOFA (AUROC, 0.84) and APACHE II (AUROC, 0.84). Next, we selected the critical values of PDLS, SOFA and APACHE II with high sensitivity and specificity in predicting 28-day mortality by ROC curve analysis. The sensitivities, specificities, positive/negative predictive values and positive/negative likelihood ratios (LR+/-) of PDLS, SOFA and APACHE $\triangle$ for mortality are shown in Table 5.

\section{Discussion}

Biomarkers and clinical scoring systems can provide powerful assistance for clinicians to Identify sepsis in the early stage of ED. In this research, we investigated the combinations of biomarkers including PCT, $\mathrm{DDi}$, and lactate to predict the severity of sepsis. We found that higher PDLS were associated with more severe sepsis and more adverse outcomes. After adjusting for confounding factors, increased PDLS was an independent predictor of 28-day mortality, MV, AICU, VD, and CRRT, regardless of sepsis severity. Compared to SOFA and APACHE II, PDLS can provide more information on predicting 28-day adverse outcomes associated with sepsis. Therefore, our results suggest that PDLS is a valuable tool for identifying high-risk sepsis patients during early ED admissions.

In order to introduce new biomarker combinations into clinical practice, biomarkers should be offered as routine tests in clinical laboratories, along with standard laboratory tests. In addition, only a limited number of parameters are required for the clinical scoring system due to the limited time patients spend in the ED. PCT has been studied as a biomarker for bacterial infections and disease severity in infectious diseases. PCT is the precursor of calcitonin and is physiologically produced by thyroid cells. Moreover, it is also synthesized outside the thyroid gland in bacterial infections and rises rapidly in response to systemic infections. Therefore, it is often referred to as the most likely biomarker to replace CRP[35]. However, PCT has not yet played a role in routine care in ED[36]. Combining PCT with other biomarkers, we found an increase in predictive value on 28-day mortality, MV, VD, AICU, and CRRT. Therefore, as performed in multiple studies, the combination of PCT with other biomarkers may be a key to be adopted as part of routine care.

The proinflammatory response to sepsis results in activation of the coagulation system and inhibition of the anticoagulant mechanism and fibrinolysis[37-39] During sepsis, platelet activation and thrombosis contribute to developing complications such as DIC, multiple organ failure, and acute lung and kidney injuries[37, 38, 40]. Adamzik et al. have shown that high levels of DDi, a sensitive biomarker for bedside monitoring of thrombi, are associated with 28-day mortality in patients with infection or sepsis found in $\mathrm{ED}[41]$. In some studies, other thrombotic biomarkers, such as fibrinogen and PLT, have been associated with the risk of sepsis; However, reported prognostic values are conflicting[37, 38]. In our study, lactate was simultaneously combined with other biomarkers. We found a high predictive value for 1-month mortality in two studies using lactate combined with other biomarkers or clinical scoring systems[42]. 
Unlike several novel biomarkers, lactate is widely used as a standard measurement during emergency examinations. Therefore, lactate is a vital biomarker to evaluate the severity of ED sepsis.

In this study, we combined three essential and readily available biomarkers from multiple mechanisms of sepsis pathophysiology, and finally created the PDLS biomarker scoring system. APACHE II and SOFA scores are used to predict mortality in septic patients admitted to the ICU, but these data are not available in the early stage of ED admission. In this current research, PDLS was based on inflammation, thrombosis, and tissue perfusion levels and composed of three simple biomarkers for routine and bedside detection in sepsis patients admitted to ED. PDLS showed higher prognostic accuracy in terms of short-term mortality compared to APACHE II and SOFA (Table 4). Furthermore, our study revealed that PDLS has higher sensitivity and specificity than SOFA and APACHE II (Table 5). Thus, PDLS may help stratify high-risk patients with different diseases; However, this hypothesis needs to be confirmed by larger well-designed studies.

Our study has several limitations. First of all, the study is not prospective but retrospective. Undoubtedly, the inherent bias in retrospective studies is unavoidable. Secondly, this was a single-center, retrospective cohort study that did not investigate long-term follow-up of enrolled patients. Thirdly, we solely recorded biomarkers investigated in the ED; however, the variation of these biomarkers at different time points have not been detected or recorded. Finally, prospective studies are warranted, and better predictors of outcome need to be explored by future researchers

\section{Conclusions}

PDLS was an independent prognostic evaluation system for patients with ED sepsis. It may help stratify sepsis patients based on the risk of early 28-day mortality and other adverse outcomes after ED admission.

\section{Abbreviations}

PDLS, scoring system using the combination of PCT, DDi, and lactate; ED, emergency department; MV, mechanical ventilation; VD, vasoactive drugs; AICU, admission to the intensive care unit; CRRT, continuous renal replacement therapy; ROC, receiver operating characteristic; SOFA, sequential organ failure assessment; APACHE, acutePhysiology and chronic health evaluation; WHO, world health organization; qSOFA, quick sequential organ failure assessment; SIRS, systemic inflammatory response syndrome; MEWS, modified early warning score; MEDS, mortality in emergency department sepsis; PCT, procalcitonin; CRP, C-reactive protein; DDi, fibrin D-dimer; DBP, diastolic blood pressure; SBP, systolic blood pressure; $\mathrm{PO}_{2}$, partial pressure of oxygen;lQR, interquartile range.

\section{Declarations}

Acknowledgements 
We wish to thank our colleagues at Department of Emergency, Sir Run Run Shaw Hospital for their help and advice, Dr.Yucai Hong and Dr. Xuchang Qin for his expert advice assistance in this study.

\section{Authors' contributions}

YSM: acquisition of the data, drafting of the manuscript. LFX: analysis and interpretation of the data. The author(s) read and approved the final manuscript.

\section{Funding}

None.

\section{Availability of data and materials}

The datasets used during the current study are available from the corresponding author on reasonable request.

\section{Ethics approval and consent to participate}

The authors are accountable for all aspects of the work in ensuring that questions related to the accuracy or integrity of any part of the work are appropriately investigated and resolved. We were approved by the Ethics Committee of Sir Run Run Shaw Hospital of Zhejiang University. No.: 20210504-30. All of the patients provided written informed consent.

\section{Consent for publication}

Not applicable.

\section{Competing interests}

Authors reported no conflict of interest.

\section{References}

1. Singer, M., C. S. Deutschman, C. W. Seymour, M. Shankar-Hari, D. Annane, M. Bauer, R. Bellomo, G. R. Bernard, J. D. Chiche, C. M. Coopersmith, R. S. Hotchkiss, M. M. Levy, J. C. Marshall, G. S. Martin, S. M. Opal, G. D. Rubenfeld, T. van der Poll, J. L. Vincent, and D. C. Angus. "The Third International Consensus Definitions for Sepsis and Septic Shock (Sepsis-3)." Jama 315, no. 8 (2016): 801-10. https://doi.org/10.1001/jama.2016.0287

2. Reinhart, K., R. Daniels, N. Kissoon, F. R. Machado, R. D. Schachter, and S. Finfer. "Recognizing Sepsis as a Global Health Priority - a Who Resolution." N Engl J Med 377, no. 5 (2017): 414-17. https://doi.org/10.1056/NEJMp1707170

3. Bouza, C., T. López-Cuadrado, Z. Saz-Parkinson, and J. M. Amate-Blanco. "Epidemiology and Recent Trends of Severe Sepsis in Spain: A Nationwide Population-Based Analysis (2006-2011)." BMC Infect 
Dis 14 (2014): 3863. https://doi.org/10.1186/s12879-014-0717-7

4. Dombrovskiy, V. Y., A. A. Martin, J. Sunderram, and H. L. Paz. "Rapid Increase in Hospitalization and Mortality Rates for Severe Sepsis in the United States: A Trend Analysis from 1993 to 2003." Crit Care Med 35, no. 5 (2007): 1244-50. https://doi.org/10.1097/01.Ccm.0000261890.41311.E9

5. Shen, H. N., C. L. Lu, and H. H. Yang. "Epidemiologic Trend of Severe Sepsis in Taiwan from 1997 through 2006." Chest 138, no. 2 (2010): 298-304. https://doi.org/10.1378/chest.09-2205

6. Angus, D. C., W. T. Linde-Zwirble, J. Lidicker, G. Clermont, J. Carcillo, and M. R. Pinsky. "Epidemiology of Severe Sepsis in the United States: Analysis of Incidence, Outcome, and Associated Costs of Care." Crit Care Med 29, no. 7 (2001): 1303-10. https://doi.org/10.1097/00003246-200107000-00002

7. Caironi, P., G. Tognoni, S. Masson, R. Fumagalli, A. Pesenti, M. Romero, C. Fanizza, L. Caspani, S. Faenza, G. Grasselli, G. Iapichino, M. Antonelli, V. Parrini, G. Fiore, R. Latini, L. Gattinoni, and Albios Study Investigators. "Albumin Replacement in Patients with Severe Sepsis or Septic Shock." N Engl J Med 370, no. 15 (2014): 1412-21. https://doi.org/10.1056/NEJMoa1305727

8. Gaieski, D. F., J. M. Edwards, M. J. Kallan, M. E. Mikkelsen, M. Goyal, and B. G. Carr. "The Relationship between Hospital Volume and Mortality in Severe Sepsis." Am J Respir Crit Care Med 190, no. 6 (2014): 665-74. https://doi.org/10.1164/rccm.201402-02890C

9. Adrie, C., C. Alberti, C. Chaix-Couturier, E. Azoulay, A. De Lassence, Y. Cohen, P. Meshaka, C. Cheval, M. Thuong, G. Troché, M. Garrouste-Orgeas, and J. F. Timsit. "Epidemiology and Economic Evaluation of Severe Sepsis in France: Age, Severity, Infection Site, and Place of Acquisition (Community, Hospital, or Intensive Care Unit) as Determinants of Workload and Cost." J Crit Care 20, no. 1 (2005): 46-58. https://doi.org/10.1016/j.jcrc.2004.10.005

10. Leisman, D. E., C. Angel, S. M. Schneider, J. A. D'Amore, J. K. D'Angelo, and M. E. Doerfler. "Sepsis Presenting in Hospitals Versus Emergency Departments: Demographic, Resuscitation, and Outcome Patterns in a Multicenter Retrospective Cohort." J Hosp Med 14, no. 6 (2019): 340-48. https://doi.org/10.12788/jhm.3188

11. Levy, M. M., R. P. Dellinger, S. R. Townsend, W. T. Linde-Zwirble, J. C. Marshall, J. Bion, C. Schorr, A. Artigas, G. Ramsay, R. Beale, M. M. Parker, H. Gerlach, K. Reinhart, E. Silva, M. Harvey, S. Regan, and D. C. Angus. "The Surviving Sepsis Campaign: Results of an International Guideline-Based Performance Improvement Program Targeting Severe Sepsis." Intensive Care Med36, no. 2 (2010): 222-31. https://doi.org/10.1007/s00134-009-1738-3

12. Milano, P. K., S. A. Desai, E. A. Eiting, E. F. Hofmann, C. N. Lam, and M. Menchine. "Sepsis Bundle Adherence Is Associated with Improved Survival in Severe Sepsis or Septic Shock." West J Emerg Med 19, no. 5 (2018): 774-81. https://doi.org/10.5811/westjem.2018.7.37651

13. Giamarellos-Bourboulis, E. J., A. Norrby-Teglund, V. Mylona, A. Savva, I. Tsangaris, I. Dimopoulou, M. Mouktaroudi, M. Raftogiannis, M. Georgitsi, A. Linnér, G. Adamis, A. Antonopoulou, E. Apostolidou, M. Chrisofos, C. Katsenos, I. Koutelidakis, K. Kotzampassi, G. Koratzanis, M. Koupetori, I. Kritselis, K. Lymberopoulou, K. Mandragos, A. Marioli, J. Sundén-Cullberg, A. Mega, A. Prekates, C. Routsi, C. Gogos, C. J. Treutiger, A. Armaganidis, and G. Dimopoulos. "Risk Assessment in Sepsis: A New 
Prognostication Rule by Apache li Score and Serum Soluble Urokinase Plasminogen Activator Receptor." Crit Care 16, no. 4 (2012): R149. https://doi.org/10.1186/cc11463

14. Churpek, M. M., F. J. Zadravecz, C. Winslow, M. D. Howell, and D. P. Edelson. "Incidence and Prognostic Value of the Systemic Inflammatory Response Syndrome and Organ Dysfunctions in Ward Patients." Am J Respir Crit Care Med 192, no. 8 (2015): 958-64. https://doi.org/10.1164/rccm.201502-02750C

15. Corfield, A. R., F. Lees, I. Zealley, G. Houston, S. Dickie, K. Ward, and C. McGuffie. "Utility of a Single Early Warning Score in Patients with Sepsis in the Emergency Department." Emerg Med J 31, no. 6 (2014): 482-7. https://doi.org/10.1136/emermed-2012-202186

16. Liu, B., Y. X. Chen, Q. Yin, Y. Z. Zhao, and C. S. Li. "Diagnostic Value and Prognostic Evaluation of Presepsin for Sepsis in an Emergency Department." Crit Care 17, no. 5 (2013): R244. https://doi.org/10.1186/cc13070

17. Knaus, W. A., E. A. Draper, D. P. Wagner, and J. E. Zimmerman. "Apache li: A Severity of Disease Classification System." Crit Care Med 13, no. 10 (1985): 818-29.

18. Raith, E. P., A. A. Udy, M. Bailey, S. McGloughlin, C. Maclsaac, R. Bellomo, D. V. Pilcher, Australian, Outcomes New Zealand Intensive Care Society Centre for, and Evaluation Resource. "Prognostic Accuracy of the Sofa Score, Sirs Criteria, and Qsofa Score for in-Hospital Mortality among Adults with Suspected Infection Admitted to the Intensive Care Unit." Jama 317, no. 3 (2017): 290-300. https://doi.org/10.1001/jama.2016.20328

19. Seymour, C. W., V. X. Liu, T. J. Iwashyna, F. M. Brunkhorst, T. D. Rea, A. Scherag, G. Rubenfeld, J. M. Kahn, M. Shankar-Hari, M. Singer, C. S. Deutschman, G. J. Escobar, and D. C. Angus. "Assessment of Clinical Criteria for Sepsis: For the Third International Consensus Definitions for Sepsis and Septic Shock (Sepsis-3)." Jama 315, no. 8 (2016): 762-74. https://doi.org/10.1001/jama.2016.0288

20. Hotchkiss, R. S., and I. E. Karl. "The Pathophysiology and Treatment of Sepsis." N Engl J Med 348, no. 2 (2003): 138-50. https://doi.org/10.1056/NEJMra021333

21. Pierrakos, C., and J. L. Vincent. "Sepsis Biomarkers: A Review." Crit Care 14, no. 1 (2010): R15. https://doi.org/10.1186/cc8872

22. Pierrakos, C., D. Velissaris, M. Bisdorff, J. C. Marshall, and J. L. Vincent. "Biomarkers of Sepsis: Time for a Reappraisal." Crit Care 24, no. 1 (2020): 287. https://doi.org/10.1186/s13054-020-02993-5

23. Müller, F., M. Christ-Crain, T. Bregenzer, M. Krause, W. Zimmerli, B. Mueller, and P. Schuetz. "Procalcitonin Levels Predict Bacteremia in Patients with Community-Acquired Pneumonia: A Prospective Cohort Trial." Chest 138, no. 1 (2010): 121-9. https://doi.org/10.1378/chest.09-2920

24. van Nieuwkoop, C., T. N. Bonten, J. W. van't Wout, E. J. Kuijper, G. H. Groeneveld, M. J. Becker, T. Koster, G. H. Wattel-Louis, N. M. Delfos, H. C. Ablij, E. M. Leyten, and J. T. van Dissel. "Procalcitonin Reflects Bacteremia and Bacterial Load in Urosepsis Syndrome: A Prospective Observational Study." Crit Care 14, no. 6 (2010): R206. https://doi.org/10.1186/cc9328

25. Schuetz, P., B. Mueller, and A. Trampuz. "Serum Procalcitonin for Discrimination of Blood Contamination from Bloodstream Infection Due to Coagulase-Negative Staphylococci." Infection 35, 
no. 5 (2007): 352-5. https://doi.org/10.1007/s15010-007-7065-0

26. Haeuptle, J., R. Zaborsky, R. Fiumefreddo, A. Trampuz, I. Steffen, R. Frei, M. Christ-Crain, B. Müller, and P. Schuetz. "Prognostic Value of Procalcitonin in Legionella Pneumonia." Eur J Clin Microbiol Infect Dis 28, no. 1 (2009): 55-60. https://doi.org/10.1007/s10096-008-0592-5

27. Schuetz, P., I. Suter-Widmer, A. Chaudri, M. Christ-Crain, W. Zimmerli, and B. Mueller. "Prognostic Value of Procalcitonin in Community-Acquired Pneumonia." Eur Respir J 37, no. 2 (2011): 384-92. https://doi.org/10.1183/09031936.00035610

28. Schuetz, P., D. N. Amin, and J. L. Greenwald. "Role of Procalcitonin in Managing Adult Patients with Respiratory Tract Infections." Chest 141, no. 4 (2012): 1063-73. https://doi.org/10.1378/chest.112430

29. Levi, M., and M. Schultz. "Coagulopathy and Platelet Disorders in Critically III Patients." Minerva Anestesiol 76, no. 10 (2010): 851-9.

30. Kinasewitz, G. T., S. B. Yan, B. Basson, P. Comp, J. A. Russell, A. Cariou, S. L. Um, B. Utterback, P. F. Laterre, and J. F. Dhainaut. "Universal Changes in Biomarkers of Coagulation and Inflammation Occur in Patients with Severe Sepsis, Regardless of Causative Micro-Organism [Isrctn74215569]." Crit Care 8, no. 2 (2004): R82-90. https://doi.org/10.1186/cc2459

31. Deitcher, S. R., and P. R. Eisenberg. "Elevated Concentrations of Cross-Linked Fibrin Degradation Products in Plasma. An Early Marker of Gram-Negative Bacteremia." Chest 103, no. 4 (1993): 110712. https://doi.org/10.1378/chest.103.4.1107

32. Hill, A. V., and H. Lupton. "Muscular Exercise, Lactic Acid, and the Supply and Utilization of Oxygen." Qjm os-16, no. 62 (1923): 135-71. https://doi.org/10.1093/qjmed/os-16.62.135

33. Liu, Z., Z. Meng, Y. Li, J. Zhao, S. Wu, S. Gou, and H. Wu. "Prognostic Accuracy of the Serum Lactate Level, the Sofa Score and the Qsofa Score for Mortality among Adults with Sepsis." Scand J Trauma Resusc Emerg Med 27, no. 1 (2019): 51. https://doi.org/10.1186/s13049-019-0609-3

34. Vijayan, A. L., Vanimaya, S. Ravindran, R. Saikant, S. Lakshmi, R. Kartik, and M. G. "Procalcitonin: A Promising Diagnostic Marker for Sepsis and Antibiotic Therapy." J Intensive Care 5 (2017): 51. https://doi.org/10.1186/s40560-017-0246-8

35. van der Does, Y., M. Limper, K. E. Jie, S. C. E. Schuit, H. Jansen, N. Pernot, J. van Rosmalen, M. J. Poley, C. Ramakers, P. Patka, E. C. M. van Gorp, and P. P. M. Rood. "Procalcitonin-Guided Antibiotic Therapy in Patients with Fever in a General Emergency Department Population: A Multicentre NonInferiority Randomized Clinical Trial (Hitemp Study)." Clin Microbiol Infect 24, no. 12 (2018): 128289. https://doi.org/10.1016/j.cmi.2018.05.011

36. Semeraro, N., C. T. Ammollo, F. Semeraro, and M. Colucci. "Sepsis, Thrombosis and Organ Dysfunction." Thromb Res 129, no. 3 (2012): 290-5. https://doi.org/10.1016/j.thromres.2011.10.013

37. de Stoppelaar, S. F., C. van 't Veer, and T. van der Poll. "The Role of Platelets in Sepsis." Thromb Haemost 112, no. 4 (2014): 666-77. https://doi.org/10.1160/th14-02-0126

38. Lupu, F., R. S. Keshari, J. D. Lambris, and K. M. Coggeshall. "Crosstalk between the Coagulation and Complement Systems in Sepsis." Thromb Res 133 Suppl 1, no. 01 (2014): S28-31. 
https://doi.org/10.1016/j.thromres.2014.03.014

39. Levi, M., and T. van der Poll. "Coagulation and Sepsis." Thromb Res 149 (2017): 38-44. https://doi.org/10.1016/j.thromres.2016.11.007

40. Adamzik, M., M. Eggmann, U. H. Frey, K. Görlinger, M. Bröcker-Preuss, G. Marggraf, F. Saner, H. Eggebrecht, J. Peters, and M. Hartmann. "Comparison of Thromboelastometry with Procalcitonin, Interleukin 6, and C-Reactive Protein as Diagnostic Tests for Severe Sepsis in Critically III Adults." Crit Care 14, no. 5 (2010): R178. https://doi.org/10.1186/cc9284

41. Viallon, A., S. Guyomarc'h, O. Marjollet, C. Berger, A. Carricajo, F. Robert, S. Laporte, C. Lambert, Y. Page, F. Zéni, and J. C. Bertrand. "Can Emergency Physicians Identify a High Mortality Subgroup of Patients with Sepsis: Role of Procalcitonin." Eur J Emerg Med 15, no. 1 (2008): 26-33.

https://doi.org/10.1097/MEJ.0b013e3280ec539b

42. Chen, Y. X., and C. S. Li. "The Prognostic and Risk-Stratified Value of Heart-Type Fatty Acid-Binding Protein in Septic Patients in the Emergency Department." J Crit Care 29, no. 4 (2014): 512-6. https://doi.org/10.1016/j.jcrc.2014.03.026

\section{Tables}

Table 1 Baseline characteristics, vital signs, laboratory parameters, and outcomes of patients with sepsis. 
Patient characteristics

All $(n=1001)$

Survive $(\mathrm{n}=884)$

Mortality $(n=117) \quad P$

Age, year

73 (61-83)

73 (61-83)

$78(68-85)$

0.01

Male, n (\%)

643 (64.2)

$558(63.1)$

$85(72.6)$

0.43

Lung disease, $\mathrm{n}(\%)$

$148(14.8)$

$126(14.3)$

$22(18.8)$

0.19

Heart failure, $n(\%)$

$147(14.7)$

$102(11.6)$

$21(17.9)$

0.06

Peripheral vascular disease, $\mathrm{n} \quad 43$ (4.3)

$37(4.2)$

$6(5.1)$

0.63

(\%)

\begin{tabular}{|c|c|c|c|c|}
\hline Dementia, n (\%) & $53(5.3)$ & $40(4.5)$ & $13(11.1)$ & 0.03 \\
\hline Rheumatologic disease, $\mathrm{n}(\%)$ & $87(8.7)$ & $77(8.7)$ & $10(8.5)$ & 0.95 \\
\hline Diabetes, n (\%) & $174(17.4)$ & $152(17.2)$ & $22(18.8)$ & 0.67 \\
\hline Renal disease, n (\%) & $47(4.7)$ & $41(5.1)$ & $6(4.6)$ & 0.81 \\
\hline Cerebrovascular disease, $\mathrm{n}(\%)$ & $108(10.8)$ & $92(10.4)$ & $16(13.7)$ & 0.63 \\
\hline Tumor, n (\%) & $128(12.8)$ & $102(11.6)$ & $26(22.6)$ & 0.01 \\
\hline Hypertension & $451(45.1)$ & $400(45.2)$ & $51(43.6)$ & 0.74 \\
\hline HR, beats/ min & $101(87-116)$ & $100(87-113)$ & $108(101-131)$ & $<0.01$ \\
\hline $\mathrm{RR}$, beats / $\mathrm{min}$ & $21(20-24)$ & $21(20-23)$ & $25(20-30)$ & $<0.01$ \\
\hline SBP, mmHg & $125(110-143)$ & $127(113-145)$ & $90(78-127)$ & $<0.01$ \\
\hline $\mathrm{DBP}, \mathrm{mmHg}$ & $72(61-84)$ & $72(62-84)$ & $58(45-80)$ & $<0.01$ \\
\hline $\mathrm{T},{ }^{\circ} \mathrm{C}$ & $37.3(36.7-38.3)$ & $37.3(36.7-38.1)$ & $38.5(37.0-39.3)$ & $<0.01$ \\
\hline $\mathrm{SPO}_{2}, \%$ & $90(86-93)$ & $91(87-93)$ & $79(74-85)$ & $<0.01$ \\
\hline WBC, $10^{9} / \mathrm{L}$ & $13.4(9.2-16.7)$ & $13.3(9.1-16.5)$ & $14.7(10.3-20.8)$ & 0.01 \\
\hline Hemoglobin, g/ L & $121(104-139.5)$ & $121(106-140)$ & $120(90.5-136)$ & 0.35 \\
\hline Platelet, $10^{9} / \mathrm{L}$ & $\begin{array}{l}161(114.5- \\
228.5)\end{array}$ & $\begin{array}{l}167(120- \\
233.5)\end{array}$ & $126(68.5-189)$ & $<0.01$ \\
\hline CRP, mg/ L & $134(70.2-215)$ & $\begin{array}{l}133.9(67.7- \\
213)\end{array}$ & $\begin{array}{l}144.4(89.4- \\
235.5)\end{array}$ & 0.45 \\
\hline Albumin, $\mathrm{g} / \mathrm{L}$ & $33(28.5-37.4)$ & $33.6(29.2-38)$ & $29(24.2-33.6)$ & $<0.01$ \\
\hline $\mathrm{BUN}, \mathrm{mmol} / \mathrm{L}$ & $6.8(4.9-11.3)$ & $6.4(4.7-10.0)$ & $13(7.7-25.0)$ & $<0.01$ \\
\hline $\mathrm{CR}, \mu \mathrm{mol} / \mathrm{L}$ & $70(60-121)$ & $76(59.0-110.8)$ & $146(78.5-310.0)$ & $<0.01$ \\
\hline $\mathrm{PH}$ & 7.40 (7.35-7.45) & $7.41(7.35-7.45)$ & 7.26 (7.2-7.37) & $<0.01$ \\
\hline
\end{tabular}




\begin{tabular}{llllr}
$\mathrm{PCO}_{2}, \mathrm{mmHg}$ & $33(29.1-38.7)$ & $33(29.3-38.2)$ & $34(26.7-42.7)$ & 0.62 \\
\hline $\mathrm{PO}_{2}, \mathrm{mmHg}$ & $60(54.0-69.7)$ & $61(56.0-70.4)$ & $46(42.8-53.0)$ & $<0.01$ \\
\hline $\mathrm{PCT}, \mathrm{ng} / \mathrm{L}$ & $2(0.7-7.4)$ & $1.5(0.6-4.4)$ & $24.2(13-51.4)$ & $<0.01$ \\
\hline $\mathrm{DDI}, \mathrm{\mu mol} / \mathrm{L}$ & $2.1(1.2-3.7)$ & $1.8(1.1-3.0)$ & $5.9(4.4-8.1)$ & $<0.01$ \\
\hline Lactate, mmol/ L & $1.8(1.3-2.6)$ & $1.6(1.3-2.3)$ & $5.6(3.8-7.7)$ & $<0.01$ \\
\hline APACHE口, score & $17(11-24)$ & $14(10-20)$ & $25(22-30)$ & $<0.01$ \\
\hline $\mathrm{SOFA}, \mathrm{score}$ & $3(3-6)$ & $3(2-5)$ & $11(7-15)$ & $<0.01$ \\
\hline $\mathrm{MV}, \mathrm{n}(\%)$ & $280(28.0)$ & $170(19.2)$ & $110(94.0)$ & $<0.01$ \\
\hline $\mathrm{AICU}, \mathrm{n}(\%)$ & $431(43.1)$ & $317(35.9)$ & $114(97.4)$ & $<0.01$ \\
\hline $\mathrm{VD}, \mathrm{n}(\%)$ & $193(19.3)$ & $90(10.2)$ & $103(88.0)$ & $<0.01$ \\
\hline$C R R T, \mathrm{n}(\%)$ & $127(12.7)$ & $55(6.2)$ & $72(61.2)$ & $<0.01$
\end{tabular}

$\mathrm{HR}$, heart rate; RR, respiratory rate; SBP, systolic blood pressure; DBP, diastolic blood pressure; T, temperature; WBC, white blood cell; CRP, c-reactive protein; BUN, blood urea nitrogen; $\mathrm{Cr}$, creatinine; DDI, Ddimer $A P A C H E$, acute Physiology and Chronic Health Evaluation; SOFA, sequential organ failure assessment; MV, mechanical ventilation; AICU, admission to intensive care unit; $V D$, vasoactive drugs; $C R R T$, continuous renal replacement therapy.

Table 2: The method of calculating the combined PCT, DDi, and lactate score (PDLS)

\begin{tabular}{llll} 
PCT & DDI & Lactate & PDLS \\
\hline$<8.12$ & $<3.59$ & $<2.65$ & 0 \\
\hline$<8.12$ & $\geq 3.59$ & $<2.65$ & 1 \\
\hline$<8.12$ & $<3.59$ & $\geq 2.65$ & 1 \\
\hline$\geq 8.12$ & $<3.59$ & $<2.65$ & 1 \\
\hline$\geq 8.12$ & $\geq 3.59$ & $<2.65$ & 2 \\
\hline$<8.12$ & $\geq 3.59$ & $\geq 2.65$ & 2 \\
\hline$\geq 8.12$ & $\geq 3.59$ & $\geq 2.65$ & 2 \\
\hline$\geq 8.12$ & $\geq 3.59$ & $\geq 2.65$ & 3
\end{tabular}

PDLS, combined PCT, DDi and lactate score; PCT, procalcitonin; DDi, D-dimer.

Table 3: Relationships between clinical characteristics and the thrombo-inflammatory prognostic score in patients with sepsis. 


\begin{tabular}{|c|c|c|c|c|c|}
\hline Variable & $\begin{array}{l}\text { PDLS }=0(n= \\
558)\end{array}$ & $\begin{array}{l}\mathrm{PDLS}=1(\mathrm{n}= \\
252)\end{array}$ & $\begin{array}{l}\text { PDLS=2 }(n= \\
89)\end{array}$ & $\begin{array}{l}P D L S=3(n= \\
102)\end{array}$ & $P$ \\
\hline Age, year & $73(61-85)$ & $71.5(59-81)$ & 73 (56.5-85) & 78 (68.8-85.3) & 0.07 \\
\hline Male, n (\%) & $353(63.3 \%)$ & $152(60.3 \%)$ & 67 (75.3\%) & 71 (69.6\%) & 0.47 \\
\hline HR, beats/ min & $99(86-110)$ & 102 (87-116) & $108(97-126)$ & $120(101-130)$ & $\begin{array}{l}< \\
0.01\end{array}$ \\
\hline RR, beats/ min & $21(20-23)$ & $21(20-24)$ & $21(20-25)$ & $24(20-30)$ & 0.01 \\
\hline SBP, mmHg & $129(114-145)$ & $128(113-145)$ & $120(90-136)$ & $90(78-125)$ & $\begin{array}{l}<.01 \\
0.01\end{array}$ \\
\hline $\mathrm{DBP}, \mathrm{mmHg}$ & 74 (64-84) & $71(61-83)$ & $65(54-86)$ & $58(45-80)$ & $\begin{array}{l}< \\
0.01\end{array}$ \\
\hline $\mathrm{T},{ }^{\circ} \mathrm{C}$ & $\begin{array}{l}37.3(36.7- \\
38.1)\end{array}$ & $\begin{array}{l}37.3(36.5- \\
38.0)\end{array}$ & $\begin{array}{l}37.5(36.7- \\
38.7)\end{array}$ & 38.5 (37-39.3) & 0.01 \\
\hline $\mathrm{SPO}_{2}, \%$ & $91(88-93)$ & 89 (85-93) & 88 (82-93) & 78 (73-85) & $\begin{array}{l}< \\
0.01\end{array}$ \\
\hline WBC, $10^{9} / \mathrm{L}$ & $13.2(8.8-15.8)$ & $13.4(9.5-17.1)$ & $13.3(8.9-17.8)$ & $\begin{array}{l}15.1(10.3- \\
21.0)\end{array}$ & $\begin{array}{l}< \\
0.01\end{array}$ \\
\hline Hemoglobin, g/ L & $124(110-140)$ & $116(98-134)$ & $118(98-138)$ & $123(90-139)$ & 0.04 \\
\hline Platelet, $10^{9} / \mathrm{L}$ & $176(131-243)$ & 156 (117-221) & $130(86-190)$ & $124(67-191)$ & $<.01$ \\
\hline CRP, mg/ L & $\begin{array}{l}121.0(58.7- \\
187.0)\end{array}$ & $\begin{array}{l}144.6(77.7- \\
234.1)\end{array}$ & $\begin{array}{l}199.2(94.8- \\
261.5)\end{array}$ & $\begin{array}{l}154.5(86.6- \\
249.3)\end{array}$ & 0.02 \\
\hline Albumin, $g / L$ & $34.3(30-39)$ & $\begin{array}{l}31.7(27.9- \\
35.8)\end{array}$ & $31(26.2-36.1)$ & $\begin{array}{l}28.8(24.0- \\
34.4)\end{array}$ & 0.01 \\
\hline BUN, mmol/ L & $6.1(4.5-8.4)$ & $7.2(5.1-11.2)$ & $10.8(6.2-18.1)$ & $14.6(9.5-25.4)$ & $\begin{array}{l}0.01 \\
0.01\end{array}$ \\
\hline $\mathrm{Cr}, \mu \mathrm{mol} / \mathrm{L}$ & 74 (56-99) & $80(61-117)$ & $127(74-234)$ & $187(94-345)$ & $\begin{array}{l}0.01 \\
0.01\end{array}$ \\
\hline $\mathrm{PH}$ & $\begin{array}{l}7.41(7.36- \\
7.45)\end{array}$ & $\begin{array}{l}7.41(7.35- \\
7.45)\end{array}$ & $\begin{array}{l}7.37(7.31- \\
7.43)\end{array}$ & $\begin{array}{l}7.24(7.14- \\
7.35)\end{array}$ & $\begin{array}{l}\square \\
0.01\end{array}$ \\
\hline $\mathrm{PCO}_{2}, \mathrm{mmHg}$ & $\begin{array}{l}33.5(30.5- \\
39.0)\end{array}$ & $\begin{array}{l}32.0(28.4- \\
37.3)\end{array}$ & $\begin{array}{l}30.6(26.3- \\
37.4)\end{array}$ & $\begin{array}{l}33.9(26.7- \\
43.4)\end{array}$ & 0.39 \\
\hline $\mathrm{PO}_{2}, \mathrm{mmHg}$ & $\begin{array}{l}63.2(56.0- \\
74.2)\end{array}$ & $\begin{array}{l}59.0(55.0- \\
67.0)\end{array}$ & $\begin{array}{l}56.0(50.5- \\
65.0)\end{array}$ & $\begin{array}{l}45.5(42.0- \\
53.0)\end{array}$ & $\begin{array}{l}\square \\
0.01\end{array}$ \\
\hline APACHE $\square$, score & $13(9-18)$ & $17(12-23)$ & $20(13-28)$ & $25(20-30)$ & $\begin{array}{l}0.01 \\
0\end{array}$ \\
\hline SOFA, score & $3(2-4)$ & $4(3-6)$ & $6(4-11)$ & $11(7-15)$ & $\begin{array}{l}\square \\
0.01\end{array}$ \\
\hline
\end{tabular}




\begin{tabular}{lccccc} 
MV, n (\%) & $63(11.3 \%)$ & $76(30.2 \%)$ & $46(51.7 \%)$ & $95(93.1)$ & 0.01 \\
\hline AICU, n (\%) & $143(25.6 \%)$ & $121(48 \%)$ & $67(75.3 \%)$ & $100(98.0 \%)$ & $\square$ \\
\hline$V D, \mathrm{n}(\%)$ & $24(4.3 \%)$ & $41(16.3 \%)$ & $41(46.1 \%)$ & $87(85.3 \%)$ & $\square$ \\
\hline CRRT, n (\%) & $16(2.9 \%)$ & $22(8.7 \%)$ & $26(29.2 \%)$ & $63(61.8 \%)$ & 0.01 \\
\hline $\begin{array}{l}\text { The 28-day mortality, } \\
\text { n (\%) }\end{array}$ & $1(0.2 \%)$ & $6(2.4 \%)$ & $16(18.0 \%)$ & $94(92.2 \%)$ & 0.01 \\
\hline
\end{tabular}

$H R$, heart rate; RR, respiratory rate; SBP, systolic blood pressure; DBP, diastolic blood pressure; T, temperature; WBC, white blood cell; CRP, c-reactive protein; BUN, blood urea nitrogen; $\mathrm{Cr}$, creatinine; DDI, Ddimer; $A P A C H E$, acute Physiology and Chronic Health Evaluation; SOFA, sequential organ failure assessment; $\mathrm{MV}$, mechanical ventilation; $\mathrm{AICU}$, admission to intensive care unit; $V D$, vasoactive drugs; $C R R T$, continuous renal replacement therapy.

Table 4: Logistic regression analysis regarding correlations between clinical outcomes and PDLS.

\begin{tabular}{lllll} 
& Univariate analysis & \multicolumn{3}{l}{ Multivariate analysis } \\
\hline Outcome & OR $(95 \% \mathrm{Cl})$ & $\mathrm{P}$ & OR $(95 \% \mathrm{Cl})$ & $\mathrm{P}$ \\
\hline 28-day mortality & $22.94(13.64-38.58)$ & $<0.01$ & $21.60(11.02-42.34)$ & $<0.01$ \\
\hline MV & $3.77(3.15-4.50)$ & $<0.01$ & $2.88(2.20-3.77)$ & $<0.01$ \\
\hline AICU & $3.42(2.85-4.10)$ & $<0.01$ & $2.49(1.99-3.11)$ & $<0.01$ \\
\hline CRRT & $3.88(3.17-4.74)$ & $<0.01$ & $1.91(1.44-2.54)$ & $<0.01$ \\
\hline VD & $4.89(3.98-5.99)$ & $<0.01$ & $2.89(2.22-3.75)$ & $<0.01$
\end{tabular}

PDLS, combined PCT, DDi and lactate score; MV, mechanical ventilation; AICU, admission to intensive care unit; $V D$, vasoactive drugs; $C R R T$, continuous renal replacement therapy.

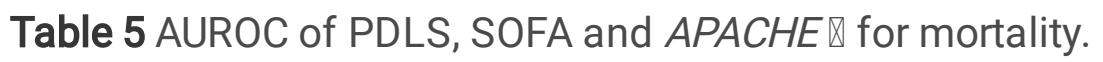

\begin{tabular}{llllllll} 
Variable & Area Under ROC curve & Sensitivity & Specifity & PPV & NPV & LR+ & LR- \\
\hline PDLS & $0.96(0.94-0.98)$ & 0.94 & 0.91 & 0.58 & 0.99 & 10.26 & 15.18 \\
\hline SOFA & $0.84(0.80-0.89)$ & 0.68 & 0.91 & 0.49 & 0.91 & 7.46 & 2.87 \\
\hline APACHE & $0.84(0.79-0.88)$ & 0.77 & 0.80 & 0.44 & 0.93 & 3.84 & 3.44
\end{tabular}


AUROC, area under the receiver operating characteristic curve; PDLS, combined PCT, DDi and lactate score; SOFA, sequential organ failure assessment; $A P A C H E$, acute Physiology and Chronic Health Evaluation; PPV, positive predictive values; NPV, negative predictive values; LR+, positive likelihood ratios; LR-, negative likelihood ratios.

\section{Figures}

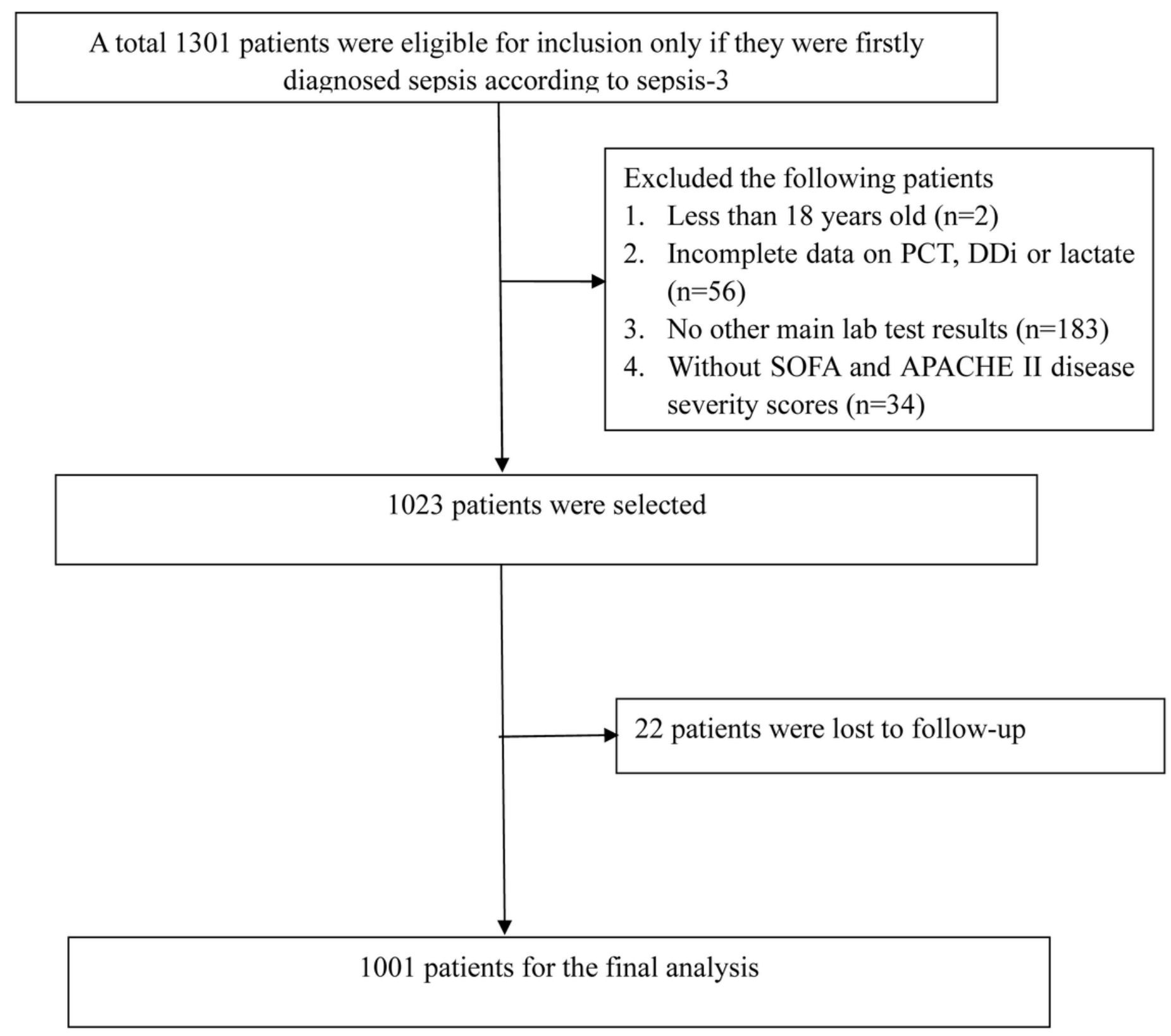

Figure 1

The detailed process of data extraction 


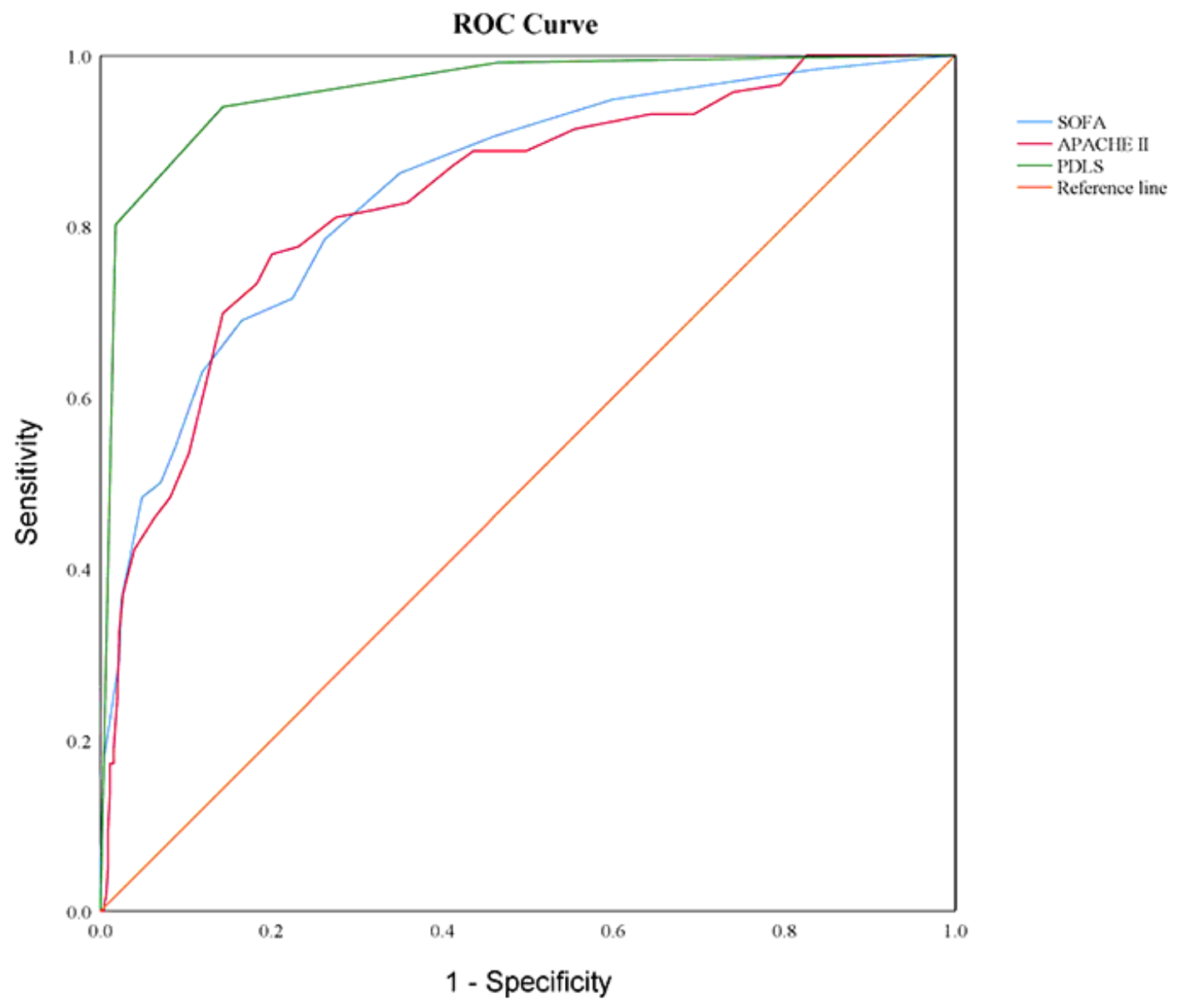

Figure 2

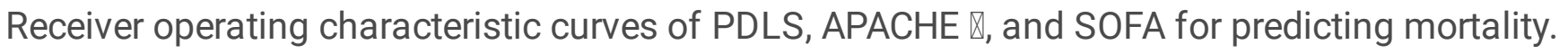

